University of Nebraska - Lincoln

DigitalCommons@University of Nebraska - Lincoln

\title{
First operational BRDF, albedo nadir reflectance products from MODIS
}

\author{
Crystal B. Schaaf \\ Boston University \\ Feng Gao \\ Boston University \\ Alan H. Strahler \\ Boston University \\ Wolfgang Lucht \\ Potsdam-Institut fur Klimafolgenforschung \\ Xiaowen Li \\ Boston University \\ See next page for additional authors
}

Follow this and additional works at: https://digitalcommons.unl.edu/nasapub

Part of the Physical Sciences and Mathematics Commons

Schaaf, Crystal B.; Gao, Feng; Strahler, Alan H.; Lucht, Wolfgang; Li, Xiaowen; Tsang, Trevor; Strugnell, Nicholas C.; Zhang, Xiaoyang; Jin, Yufang; Muller, Jan-Peter; Lewis, Philip; Barnsley, Michael; Hobson, Paul; Disney, Mathias; Roberts, Gareth; Dunderdale, Michael; Doll, Christopher; d'Entremont, Robert P.; Hu, Baoxin; Liang, Shunlin; Privette, Jeffrey L.; and Roy, David P., "First operational BRDF, albedo nadir reflectance products from MODIS" (2002). NASA Publications. 38.

https://digitalcommons.unl.edu/nasapub/38

This Article is brought to you for free and open access by the National Aeronautics and Space Administration at DigitalCommons@University of Nebraska - Lincoln. It has been accepted for inclusion in NASA Publications by an authorized administrator of DigitalCommons@University of Nebraska - Lincoln. 


\section{Authors}

Crystal B. Schaaf, Feng Gao, Alan H. Strahler, Wolfgang Lucht, Xiaowen Li, Trevor Tsang, Nicholas C. Strugnell, Xiaoyang Zhang, Yufang Jin, Jan-Peter Muller, Philip Lewis, Michael Barnsley, Paul Hobson, Mathias Disney, Gareth Roberts, Michael Dunderdale, Christopher Doll, Robert P. d'Entremont, Baoxin Hu, Shunlin Liang, Jeffrey L. Privette, and David P. Roy 


\title{
First operational BRDF, albedo nadir reflectance products from MODIS
}

\author{
Crystal B. Schaaf ${ }^{\mathrm{a}, *}$, Feng Gao ${ }^{\mathrm{a}, 1}$, Alan H. Strahler ${ }^{\mathrm{a}}$, Wolfgang Lucht ${ }^{\mathrm{b}}$, Xiaowen $\mathrm{Li}^{\mathrm{a}, 1}$, \\ Trevor Tsang ${ }^{\text {a }}$, Nicholas C. Strugnell ${ }^{\text {a }}$, Xiaoyang Zhang ${ }^{\text {a }}$, Yufang Jin ${ }^{\mathrm{a}}$, Jan-Peter Muller ${ }^{\mathrm{c}}$, \\ Philip Lewis ${ }^{\mathrm{d}}$, Michael Barnsley ${ }^{\mathrm{e}}$, Paul Hobson ${ }^{\mathrm{e}}$, Mathias Disney ${ }^{\mathrm{d}}$, Gareth Roberts ${ }^{\mathrm{d}}$, \\ Michael Dunderdale ${ }^{\mathrm{c}}$, Christopher Doll ${ }^{\mathrm{c}}$, Robert P. d'Entremont ${ }^{\mathrm{f}}$, Baoxin $\mathrm{Hu}^{\mathrm{g}}$, \\ Shunlin Liang ${ }^{\mathrm{h}}$, Jeffrey L. Privette ${ }^{\mathrm{i}}$, David Roy ${ }^{\mathrm{h}}$ \\ a Department of Geography and Center for Remote Sensing, Boston University, 675 Commonwealth Avenue, Boston, MA 02215, USA \\ ${ }^{\mathrm{b}}$ Potsdam-Institut für Klimafolgenforschung (PIK), Telegrafenberg C4, Postfach 6012 03, D14412 Potsdam, Germany \\ ${ }^{\mathrm{c}}$ Department of Geomatic Engineering, University College London, Gower St., London WCIE 6BT, UK \\ ${ }^{\mathrm{d}}$ Department of Geography, University College London, Gower St., London WCIE 6BT, UK \\ 'Department of Geography, University of Wales Swansea, Singleton Park, Swansea SA2 8PP, UK \\ ${ }^{\mathrm{f}}$ Atmospheric and Environmental Research, Inc., 131 Hartwell Ave, Lexington, MA, 02421, USA \\ ${ }^{\mathrm{g}}$ Department of Physics and Astronomy, York University, 4780 Keele Street, Toronto, Ontario, M3J 1P3, Canada \\ ${ }^{\mathrm{h}}$ Department of Geography, Lefrak Hall, University of Maryland, College Park, MD 20742, USA \\ ${ }^{\mathrm{i}}$ NASA Goddard Space Flight Center, Code 923, Biospheric Sciences, Greenbelt, MD 20771, USA
}

Received 26 March 2001; received in revised form 15 November 2001; accepted 12 February 2002

\begin{abstract}
With the launch of NASA's Terra satellite and the MODerate Resolution Imaging Spectroradiometer (MODIS), operational Bidirectional Reflectance Distribution Function (BRDF) and albedo products are now being made available to the scientific community. The MODIS $\mathrm{BRDF} /$ Albedo algorithm makes use of a semiempirical kernel-driven bidirectional reflectance model and multidate, multispectral data to provide global $1-\mathrm{km}$ gridded and tiled products of the land surface every 16 days. These products include directional hemispherical albedo (black-sky albedo), bihemispherical albedo (white-sky albedo), Nadir BRDF-Adjusted surface Reflectances (NBAR), model parameters describing the BRDF, and extensive quality assurance information. The algorithm has been consistently producing albedo and NBAR for the public since July 2000. Initial evaluations indicate a stable BRDF/Albedo Product, where, for example, the spatial and temporal progression of phenological characteristics is easily detected in the NBAR and albedo results. These early beta and provisional products auger well for the routine production of stable MODIS-derived BRDF parameters, nadir reflectances, and albedos for use by the global observation and modeling communities.
\end{abstract}

(C) 2002 Elsevier Science Inc. All rights reserved.

\section{Introduction}

The multiangle capabilities of new instruments such as the MODerate resolution Imaging Spectroradiometer (MODIS), the Multiangle Imaging SpectroRadiometer (MISR) and the POLarization and Directionality of the Earth's Reflectances (POLDER) multispectral camera (Diner et al., 1998; Justice et al., 1998; Leroy et al., 1997)

\footnotetext{
* Corresponding author. Tel.: +1-617-358-0503; fax: +1-617-353-3200.

E-mail address: schaaf@bu.edu (C.B. Schaaf).

${ }^{1}$ Also at Research Center for Remote Sensing, Beijing Normal University, Beijing, China.
}

are facilitating the characterization of the anisotropy of land surface reflectance around the globe. While instruments such as POLDER (Hautecoeur \& Leroy, 1998) and MISR (Martonchik et al., 1998; Rahman, Pinty, \& Verstraete, 1993) obtain multiple angular views within a short time span and thus provide virtually instantaneous sampling of the Bidirectional Reflectance Distribution Function (BRDF), MODIS, and other imagers such as AVHRR (d'Entremont, Barker Schaaf, Lucht, \& Strahler, 1999), SeaWIFs, Meteosat (Pinty et al., 2000a, 2000b), SPOT-4 VEG, and MERIS build up sequential angular views over a period of hours or days (Diner et al., 1999). In either case, these directional observations can be coupled with semiempirical models to describe the BRDF and integrals necessary to provide 
spectral albedos (Lucht \& Roujean, 2000). This paper provides an overview of the methods used by the operational MODIS BRDF/Albedo algorithm and presents some of the results from early evaluations of the beta and provisional products.

The operational MODIS BRDF/Albedo algorithm makes use of a kernel-driven, linear BRDF model which relies on the weighted sum of an isotropic parameter and two functions (or kernels) of viewing and illumination geometry to determine reflectance, $R$ (Roujean, Leroy, \& Deschamps, 1992).

$$
\begin{aligned}
R(\theta, v, \phi, \lambda)= & f_{\text {iso }}(\lambda)+f_{\text {vol }}(\lambda) K_{\mathrm{vol}}(\theta, v, \phi, \lambda) \\
& +f_{\text {geo }}(\lambda) K_{\text {geo }}(\theta, v, \phi, \lambda)
\end{aligned}
$$

where $\theta, v$, and $\phi$ are the solar zenith, view zenith and relative azimuth angles; $K_{k}(\theta, v, \phi, \lambda)$ are the model kernels; and $f_{k}(\lambda)$ are the spectrally dependent BRDF kernel weights or parameters. The kernel weights selected are those that best fit the available observational data.

One of these kernels, $K_{\mathrm{vol}}(\theta, v, \phi, \lambda)$, is derived from volume scattering radiative transfer models (Ross, 1981) and the other, $K_{\text {geo }}(\theta, v, \phi, \lambda)$, from surface scattering and geometric shadow casting theory ( $\mathrm{Li} \&$ Strahler, 1992). Several studies have identified this RossThickLiSparseReciprocal kernel combination as the model best suited for the operational MODIS BRDF/Albedo algorithm (Lucht, Schaaf, \& Strahler, 2000; Privette, Eck, \& Deering, 1997; Wanner, Li, \& Strahler, 1995; Wanner et al., 1997).

Initially, the operational MODIS BRDF/Albedo algorithm only makes use of MODIS data from onboard NASA's sun-synchronous Terra spacecraft to provide a global product every 16 days. While Terra has a morning equator crossing, the processing scheme is flexible enough to eventually incorporate additional MODIS observations from the afternoon equator crossing platform Aqua (launched in 2002), as well as from MISR (also on the Terra platform). The goal is to use as many remotely sensed directional reflectances as possible to characterize the BRDF frequently and to provide the global observation and modeling community with reliable and consistent surface albedos and cloud-free nadir surface reflectances.

\section{Product evaluation}

The selection of the RossThickLiSparse-Reciprocal kernels as the at-launch MODIS BRDF model was based on an extensive program of testing and analysis. This kernel combination was found to perform consistently well over a wide range of surface covers (Privette et al., 1997). The model is relatively insensitive to noisy data (Lucht \& Lewis, 2000) and performs well with even a small sampling of quality input observations (Lucht, 1998). The conversion from spectral to broadband inherent albedos is based on the modeling work of Liang, Strahlaer, and Walthall (1999) in the seven MODIS land bands.

Prelaunch validation efforts used this algorithm to process AVHRR and POLDER data taken over Jornada, NM, during field exercises in May, 1997. Coincident AVIRIS spectra were then used to convert the satellite spectral albedos to broadband measurements which were then found to be in excellent agreement with albedometer measurements acquired on the ground and spatially modeled to satellite resolution with Landsat Thematic Mapper data (Barnsley et al., 2000; Lucht, Hyman, et al., 2000).

\section{The MODIS BRDF/albedo product}

The MODIS BRDF/Albedo Science Data Product is among the MODIS. Level $31-\mathrm{km}$ land products that are provided in an Integerized Sinusoidal Grid (ISG) projection with standard tiles representing $1200 \times 1200$ pixels on the Earth (Wolfe, Roy, \& Vermote, 1998). While the projection becomes increasingly sheared with distance from the Greenwich meridian, the equal area properties of ISG mean that it is a good data storage format. Most users will want to convert the data to other, more common projections, however.

The MOD43B MODIS BRDF/Albedo algorithm provides four standard products in HDF-EOS format for each of the 289 land tiles on the globe. The first two products supply spectral (MODIS channels 1-7) and broadband $(0.3-0.7,0.7-5.0$, and $0.3-5.0 \mu \mathrm{m})$ BRDF model parameters so that the user can reconstruct the entire surface BRDF and compute the directional reflectance at any view or solar zenith angle desired. Using these same parameters, directional hemispherical reflectance (black-sky albedo) can be generated for any desired solar zenith angles and the bihemispherical reflectance (white-sky albedo) can also be computed. The RossThickLiSparseReciprocal kernel combination is the primary semiempirical model selected to provide these BRDF parameters at launch (MOD43B1). A second model choice is also computed to operationally test new and more accurate semiempirical models as they become available. In the interim, the modified Walthall empirical model is being computed (Nilson \& Kuusk, 1989).

The third operational product (MOD43B3) provides a standard suite of albedos for those users who do not wish to perform the computations (albeit simple computations, see Eq. (2)) from the BRDF model parameters provided in the first product. Black-sky and white-sky albedos are provided for seven spectral bands (MODIS channels 1-7) and the three broadbands $(0.3-0.7,0.7-3.0$, and $0.3-5.0 \mu \mathrm{m})$. The black-sky albedos are computed for the local noon solar zenith angle for each location.

The fourth operational product (MOD43B4) uses the BRDF model in Eq. (1) to generate the Nadir BRDFAdjusted Reflectances (NBAR) for MODIS bands 1-7. 
Table 1

Per-pixel quality flags for the MODIS BRDF/Albedo products

\begin{tabular}{ll}
$\begin{array}{l}\text { First 32-bit word } \\
\text { band-independent flags }\end{array}$ & $\begin{array}{l}\text { Second 32-bit word } \\
\text { band-dependent flags }\end{array}$ \\
\hline $\begin{array}{l}\text { Mandatory QA } \\
\text { Period used }\end{array}$ & $\begin{array}{l}\text { Band 1 } \\
\text { Band 2 } \\
\text { Land/water mask }\end{array}$ \\
$\begin{array}{l}\text { AM, PM, and/or MISR } \\
\text { Mean SZN of }\end{array}$ & Band 3 \\
$\quad$ observations (NBAR) & Band 5 \\
$\quad$ or SZN of local solar noon & \\
$\quad$ (black-sky albedo) & Band 6 \\
Fill value & Band 7 \\
\hline
\end{tabular}

\footnotetext{
a For each band, an indication of full or magnitude inversion is given and the quality of that inversion.
}

These are computed for the mean solar zenith angle of the 16-day period. With the launch of the Aqua platform, BRDF parameters based on the combined Terra and Aqua observations will be used to compute both a morning NBAR value (with the mean solar zenith angle of the Terra observations) and an afternoon NBAR value (with the mean solar zenith angle of the Aqua observations). The NBAR surface reflectance product aims to provide the nadir information content of Landsat-7 but at a coarser $1-\mathrm{km}$ resolution and in a global context. Since view angle effects (as well as cloud and aerosol contamination) have been removed, NBAR is ideal for applications which have traditionally had to depend on compositing methods to reduce these effects. Due to the temporal consistency of this product, it serves as the primary input to the advanced technique classifiers used in the production of the global MODIS Land Cover Science Data Product (Friedl et al., 2000).

Each operational product is associated with extensive quality assurance information so that users can reconstruct the processing methodology used for each tile or pixel if they choose. At a minimum, all BRDF/Albedo products supply a per-pixel quality flag (as do all MODIS Land products) indicating whether the algorithm produced results for that pixel and if so, whether or not the result is of the highest quality and can be used without reservation or whether (due to some uncertainties in the input or processing) the user should check the extensive additional productspecific quality assurance to make sure the output is appropriate for their application (Table 1). In addition, each operational product is accompanied by extensive metadata that provides similar quality assessments of the entire tile.

\section{Processing strategy}

The MODIS algorithm relies on sequential multiangle surface observations built up over a 16-day period to characterize the surface BRDF. The data are based on the gridded MOD09 Surface Reflectance Product values that have been corrected for aerosol and atmospheric effects (Vermote et al., 1997). The corrected surface data are first aggregated from their native channel resolution (250 or 500 $\mathrm{m})$ to a $1-\mathrm{km}$ grid (process MODAGAGG). Due to the frequent overpasses that occur at higher latitudes, as many as four observations can be acquired and retained for each day. If at least seven cloud-free observations of the surface are available during a 16-day period, a full model inversion is attempted. The available data are first evaluated to discard outliers and additional checks are performed to assure that the kernel weights (and model parameters) are positive. Finally, the weights of determination (Lucht \& Lewis, 2000) are also computed to ascertain the confidence in the product given the available angular sampling. If the data pass all of these evaluations, a full inversion is performed to establish the BRDF parameter weights that provide the best (RMSE) fit.

For those cases with insufficient or poor sampling, or a poor fit, a magnitude inversion is performed rather than a full model inversion. This follows the scheme of (Strugnell \& Lucht, 2001) where an archetypal BRDF shape has been associated a priori with each pixel on the globe. This method assumes that the BRDFs associated with a certain surface cover fall into broadly similar shapes and variations are merely a matter of degree. To capture these variations, archetypal shapes are adjusted by a multiplicative factor which best fits all of the directional observations that are available at each pixel-therefore introducing realistic within class spatial variation (Strugnell \& Lucht, 2001). Thus, a priori determination of the general shape is being used as a "first guess", and that shape is then constrained by the available observations. This method was selected after its reliability had been demonstrated through testing with globally composited AVHRR data (Strugnell, Lucht, \& Schaaf, 2001). Initially, the archetypal BRDFs are determined by fitting the RossThickLiSparse-Reciprocal semiempirical model to well-sampled field data (primarily from the PARABOLA instrument (Deering \& Leone, 1986)). However, archetypal BRDFs must also represent seasonal anisotropic variations, since, for example, the BRDF of a fully leaved deciduous forest canopy is very different from that of a bare-limbed canopy with or without snow on the ground. Therefore, the at-launch archetypal BRDFs are initially associated with each land pixel through the use of a land cover map (Loveland et al., 1999; Olson, 1994) and a seasonal model. This is only an interim solution however and over time, as stable high quality MODIS full retrievals are obtained over the globe, they themselves will replace these at-launch values and will serve as the a priori archetypal BRDFs for each global pixel (severing all connection with a land cover based method). This global archetypal database of entirely MODIS-derived representations of seasonal BRDFs may well prove to be one of the most valuable byproducts of this effort and be of particular interest to global modelers interested in using realistic land surface parameterizations of the surface anisotropy. 
It is important to note that the operational algorithm keeps track of whether snow has been associated with the daily observations by the upstream products. If the majority of days in a 16-day period have been snow-covered, then the algorithm uses only the snowy pixels to make its retrieval. On the other hand, if only a few days in a period are snowcovered, then they are discarded and a snow-free BRDF retrieval is made. Thus, the MODIS-derived archetypal database will contain both snow and snow-free representations. Flags indicating the type of retrieval made are maintained in the accompanying quality assurance fields.

In addition to the standard 1-km gridded products available in an ISG-tiled format from the EROS Data Center (EDC) Data Active Archive Center (DAAC), 5-km ISG tiled products (available from the authors), and one quarter degree spatial resolution products in the geographic projection of the Climate Modeling Grid (CMG) are also produced. The CMG products are available from the EDC DAAC.

\section{Product use}

Although sample white-sky and black-sky albedos are provided in the operational product MOD43B3, it is assumed that most users will rely on the BRDF model parameters in MOD43B1 to compute albedos with the solar illumination geometry most appropriate for their particular application. The linear nature of the kernel-driven models means that these parameters can be easily used in conjunction with either a look-up table of precomputed kernel integrals or a simple mathematical expression that captures the relatively benign solar zenith angle dependence of the black-sky albedo. The following polynomial has been found to reproduce $\alpha_{\mathrm{bs}}(\theta, \lambda)$, the fully modeled black-sky albedo, quite well (Lucht, Hyman, et al., 2000; Lucht, Schaaf, et al., 2000).

$$
\begin{aligned}
\alpha_{\mathrm{bs}}(\theta, \lambda)= & f_{\text {iso }}(\lambda)\left(g_{0 \text { iso }}+g_{1 \text { iso }} \theta^{2}+g_{2 \text { iso }} \theta^{3}\right) \\
& +f_{\text {vol }}(\lambda)\left(g_{0 \mathrm{vol}}+g_{1 \mathrm{vol}} \theta^{2}+g_{2 \mathrm{vol}} \theta^{3}\right) \\
& +f_{\text {geo }}(\lambda)\left(g_{0 \text { geo }}+g_{1 \text { geo }} \theta^{2}+g_{2 \mathrm{geo}} \theta^{3}\right)
\end{aligned}
$$

where the $g_{j k}$ coefficients are listed in Table 2, and the $f_{k}(\lambda)$ are the BRDF model kernel weights or parameters. The integrated coefficients for the white-sky albedo $\alpha_{\mathrm{ws}}(\theta, \lambda)$ are also provided.

Table 2

\begin{tabular}{llcc} 
Coefficients for Eq. (2) & & \\
\hline Term $g_{j k}$ for kernel $k$ & $k=$ Isotropic & $k=$ RossThick & $k=$ LiSparse-R \\
\hline$g_{0 \mathrm{k}}(\operatorname{term} 1)$ & 1.0 & -0.007574 & -1.284909 \\
$g_{0 \mathrm{k}}\left(\operatorname{term} \theta^{2}\right)$ & 0.0 & -0.070987 & -0.166314 \\
$g_{0 \mathrm{k}}\left(\operatorname{term} \theta^{3}\right)$ & 0.0 & 0.307588 & 0.041840 \\
White-sky & 1.0 & 0.189184 & -1.377622 \\
\hline
\end{tabular}

The albedo, $\alpha(\theta, \lambda)$, under actual atmospheric conditions can also be modeled quite accurately as an interpolation between the black-sky (direct beam) albedo and white-sky (completely diffuse) albedo as a function of the fraction of diffuse skylight $S(\theta, \tau(\lambda))$, which, in turn, is a function of optical depth $\tau$ (Lewis \& Barnsley, 1994; Lucht, Schaaf, et al., 2000).

$$
\alpha(\theta, \lambda)=\{1-S(\theta, \tau(\lambda))\} \alpha_{\mathrm{bs}}(\theta, \lambda)+S(\theta, \tau(\lambda)) \alpha_{\mathrm{ws}}(\theta, \lambda)
$$

Thus, with simple parameterizations such as these, modelers can retain complete flexibility and use the MODIS BRDF parameters to generate the albedo measures most useful to their application, as well as use the BRDF parameters directly to correct data to a common view angle, or to interpret the biophysical nature of the surface.

As mentioned, BRDF parameters are produced (via either full or magnitude inversions) for every land or coastal area which is viewed (and atmospherically corrected) at least once over a 16-day period. Land areas that remain completely cloud covered over this period are designated with fill values. The quality information associated with the BRDF parameter retrievals reflects the quality of the atmospherically corrected, cloud-cleared reflectances used as input, and the type and stability of the inversion performed.

The algorithm team personally evaluates a number of the tiles on a routine basis. These tiles will be designated by an updated science data quality flag and are selected to cover many of the 24 EOS Land Validation Core Sites (Privette, Morrisette, Justice, \& Starr, 1999) available from the Data Active Archive Center (DAAC) at the EROS Data Center (EDC) through the EOS Land Validation webpage (http:// modarch.gsfc.nasa.gov/MODIS/LAND/VAL/). These Core Sites (which represent a variety of surfaces across the globe) are being maintained so that users can easily obtain MODIS data, data from other Terra instruments, data from Landsat-7 and other high resolution imagers, ground measurements, and ancillary information to perform regional studies at these locations.

\section{Preliminary results}

While some early prototyping was accomplished with ASAS aircraft data (Lewis, Disney, Barnsley, \& Muller, 1999), the majority of the prelaunch algorithm testing was performed with AVHRR data (Chopping, 1999; d'Entremont et al., 1999; Hu, Lucht, Strahler, Schaaf, \& Smith, 2000). Although these prototyping exercises engendered confidence in the algorithm, the excellent geolocation capabilities of MODIS, the increased spectral coverage, and the state-of-the art cloud masking and atmospheric correction applied to the MODIS land bands (channels 1-7) were all expected to provide vastly superior results. The preliminary 


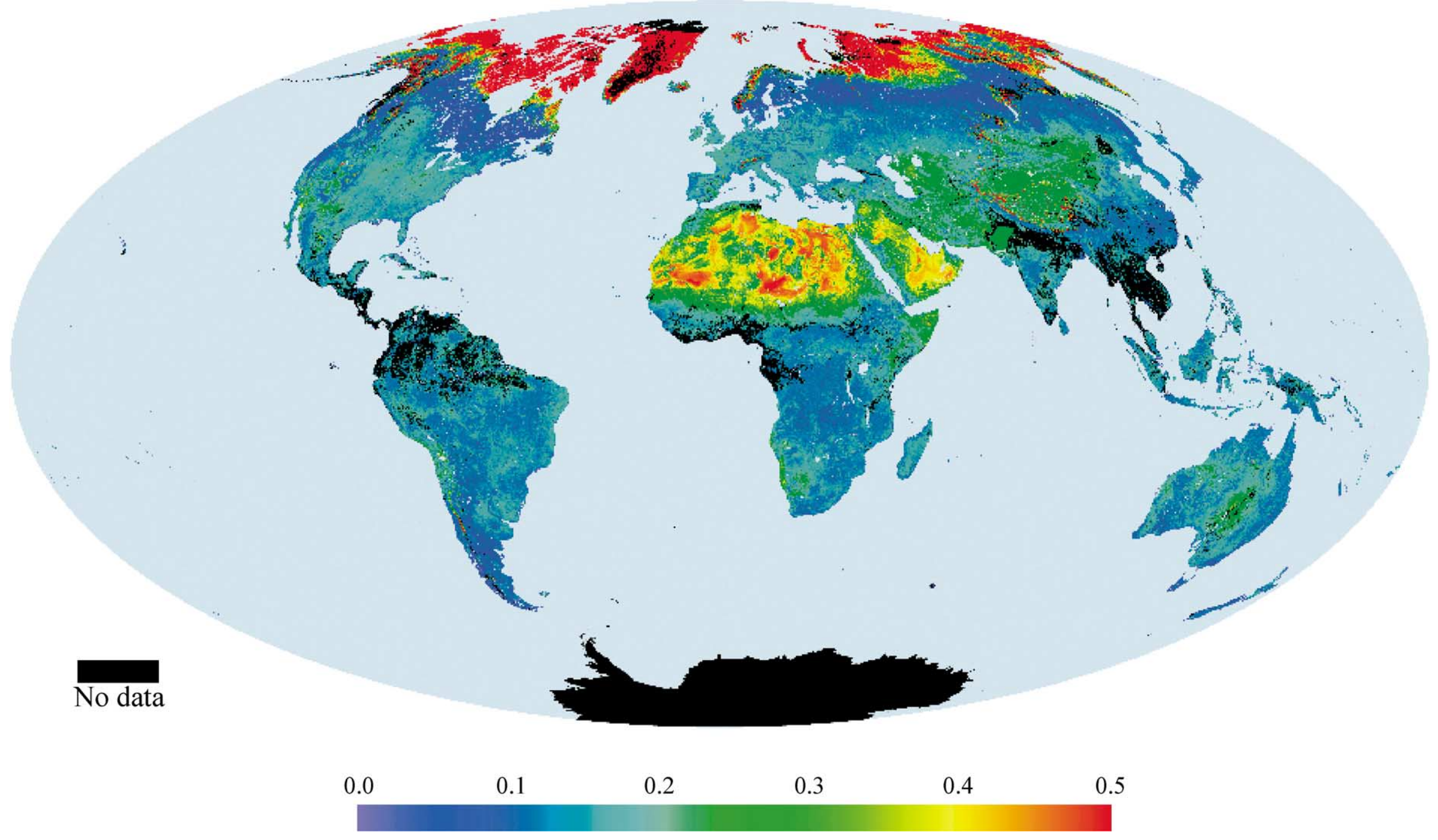

Fig. 1. Global broadband white-sky albedo $(0.3-5.0 \mu \mathrm{m})$ for the period 9-24 May 2001 (Julian Days 129-144). Hammer-Aitoff projection; 20-km resolution for display purposes. 


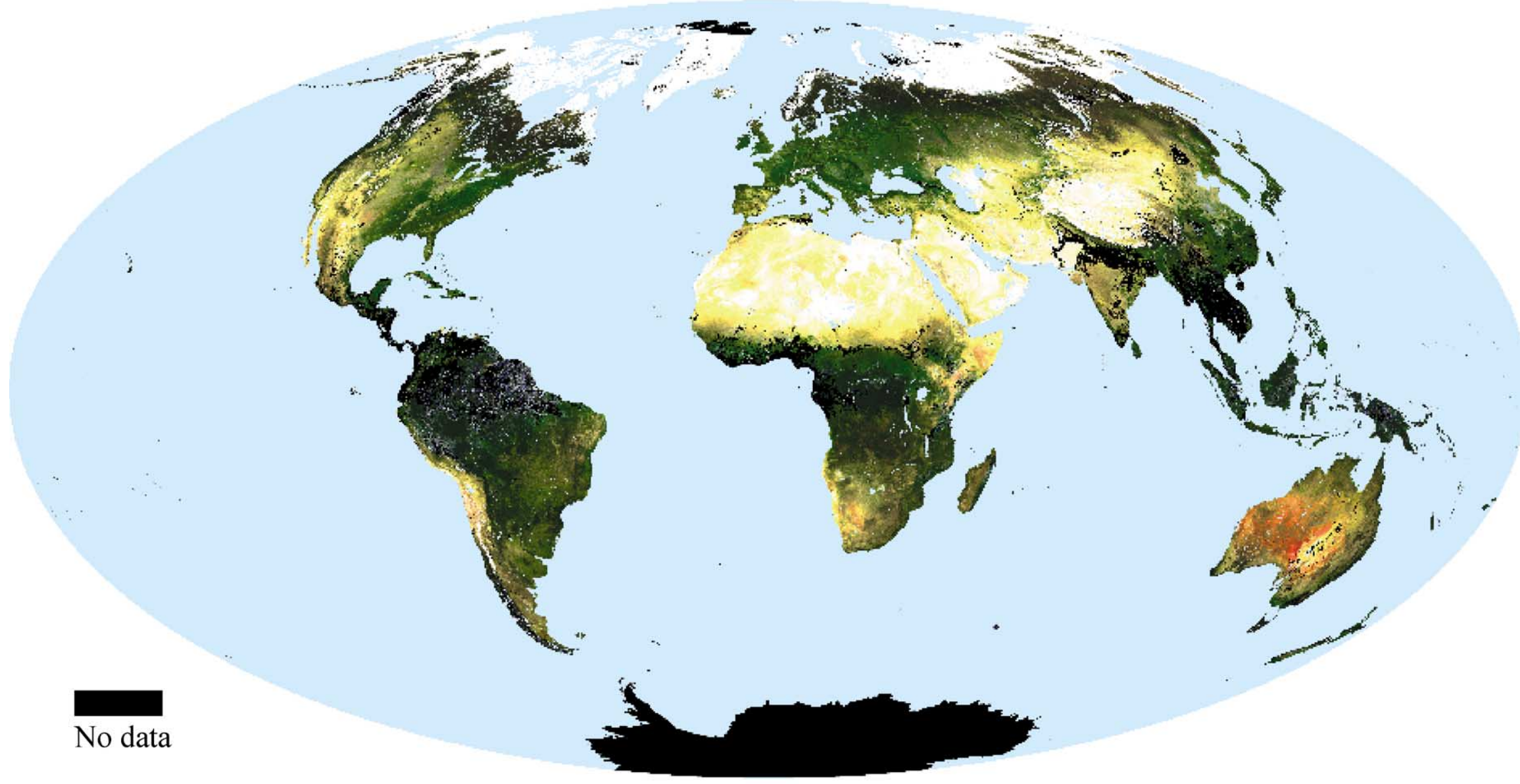

Band 1-red (0.0-0.2) Band 4-green (0.0-0.2) Band 3-blue (0.0-0.2)

Fig. 2. Global NBAR (three-channel true color composite: Band 1-Red, Band 4-Green, Band 3-Blue) for the period 9-24 May, 2001 (Julian Days 129-144). Hammer-Aitoff Projection; 20-km resolution for display purposes. 


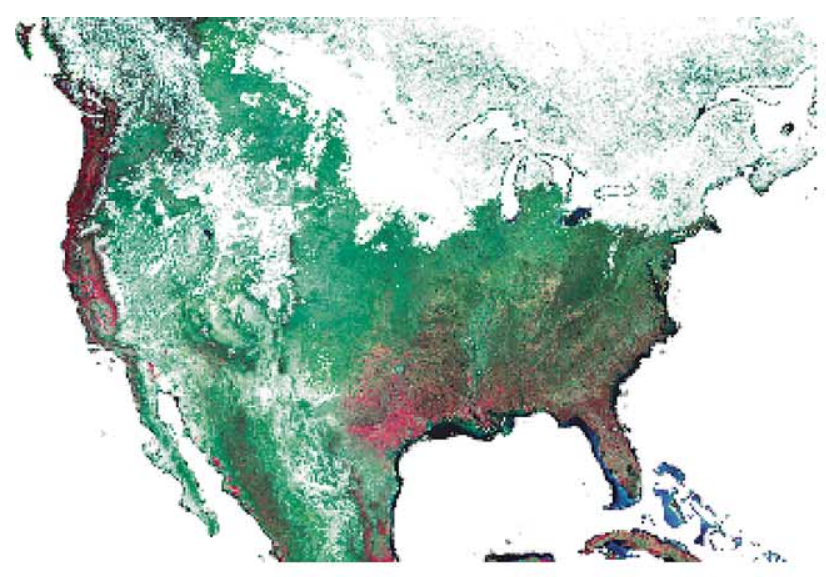

6-21 March, 2001 (Day 065)

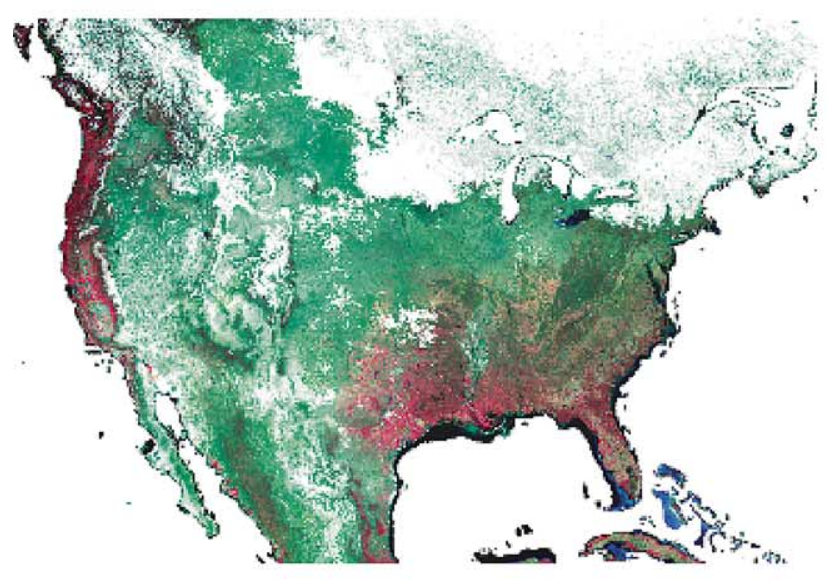

22 March - 6 April, 2001 (Day 081)

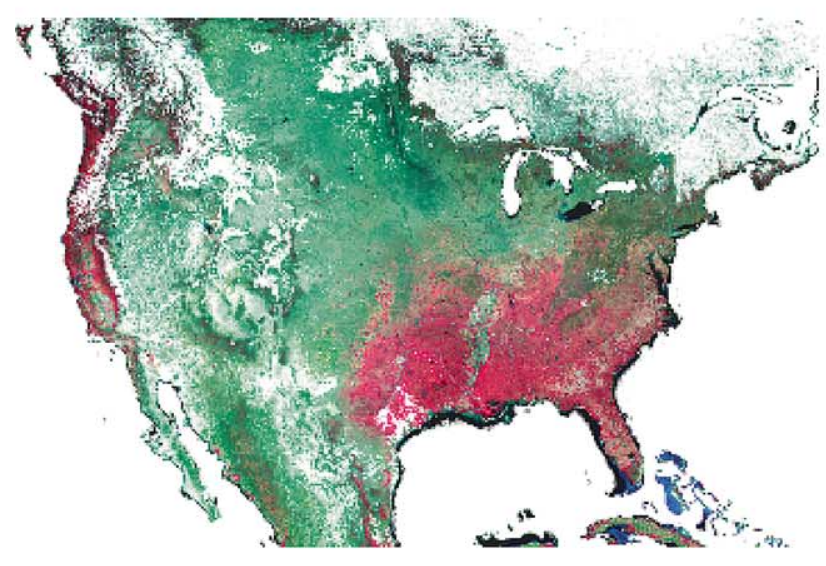

7-22 April, 2001 (Day 097)

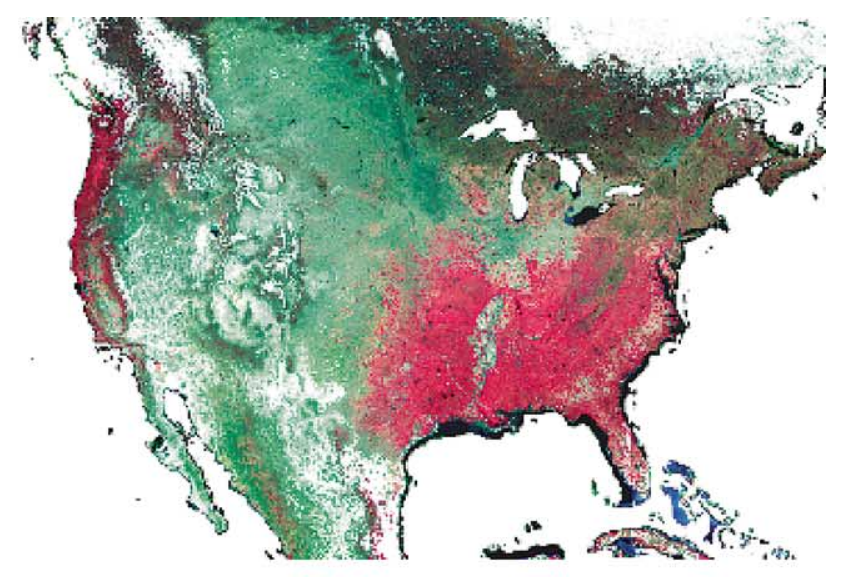

23 April - 8 May, 2001 (Day 113)

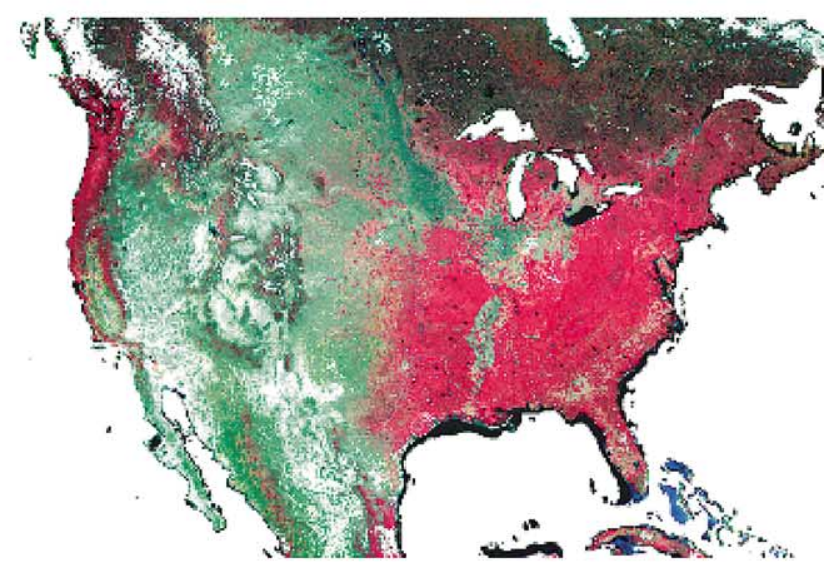

9-24 May, 2001 (Day 129)

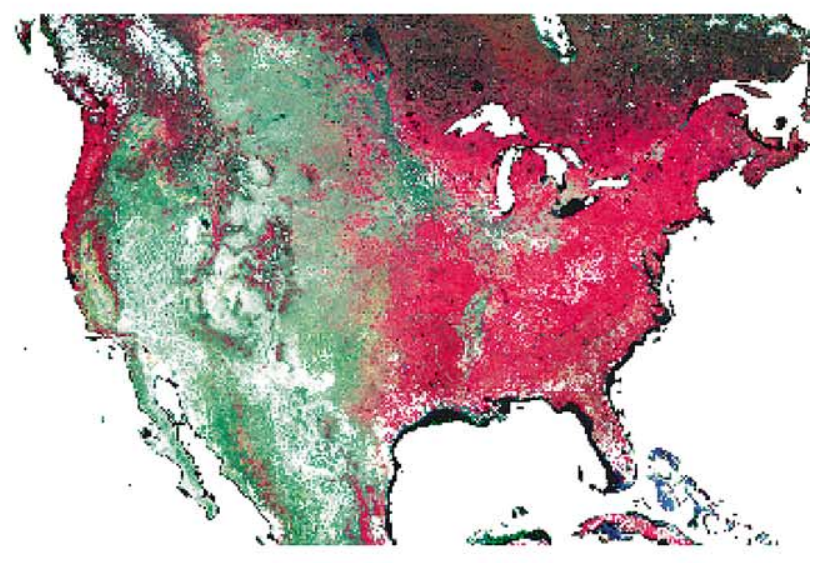

25 May - 9 June, 2001 (Day 145)

Band 2-NIR (0.1-0.4) Band 1-Red (0.0-0.16) Band 4-Green (0.0-0.18)

Fig. 3. Temporal sequence of North American NBAR (three-channel composite: NIR, Red, Green) for the period 6 March to 9 June, 2001 (Julian Days $65-$ 160). Goode's Homolosine projection. 
products (from late 2000 and early 2001) bear this expectation out.

The MODIS BRDF/Albedo Product began production in April 2000 and was released as a beta product to the general public with data from July 2000 onward. The beta results were based on early calibration efforts and on surface reflectances that had not been accurately corrected for aerosol scattering. After a number of MODIS instrument and upstream product enhancements, the MOD43B BRDF/ Albedo Products were upgraded from a beta to a provisional status from 31 October 2000 onward. The data from November 2000 to October 2001 have been utilized in the first reprocessing effort and the images in this paper reflect reprocessed results. The product continues to be qualitatively evaluated by the science team with image-based assessments and in addition, a number of rigorous field validation exercises are underway to estimate quantitative uncertainty. Validation sites include an agricultural area in Maryland, USA; a woodland region in Mongu, Zambia; an area of savanna in Skukuza, South Africa; an agricultural area in Barton Bendish, UK; and agricultural sites in Liangchen, Shunyi, and Yucheng, China.

The global broadband white-sky albedo (bihemispherical reflectance) for the 16-day period, 9-24 May 2001 (Julian Days of Year 129-144), is displayed in Fig. 1. The global Nadir BRDF-Adjusted Reflectance (NBAR) for the same period is displayed in Fig. 2 as a three-channel true color spectral composite (where NBAR provides surface reflectances that have been corrected as if they were obtained with a nadir viewing instrument). The land areas where persistent cloud cover made retrievals impossible are identified in black on both figures. To gain more of a regional view, as well as display the temporal consistency of the product, Fig. 3 provides a sequence of false color spectral composites of North American NBARs from March to June. White areas indicate fill values on these images. The spring vegetation greenup is clearly shown progressing northward on these images.

To further assess the temporal performance of NBAR from June 2000 to June 2001, results for several land cover types are plotted in Fig. 4. A large number of Land Cover Training Sites are maintained over the globe as part of the STEP database (Muchoney, Strahler, Hodges, \& LoCastro, 1999) and are used to train the advanced technique classifiers that produce the MODIS Land Cover Product (MOD12Q1). The actual land cover of these locations has been determined by expert analysis of Landsat imagery, field measurements and ancillary products. The NBAR data in southern North America that correspond to training site locations for three of these cover types were extracted. Since these are exactly the same data that are introduced to the land cover algorithm as training data, these examples also demonstrate the spectral and temporal signal the MODIS Land Cover Product classifiers use for these land cover types. Note that data were unavailable for Days 2000209 and 2001049 due to instrument and reprocessing difficulties. Of foremost interest is the consistency of the temporal signal which, even with recognition that a dynamic aerosol cor-

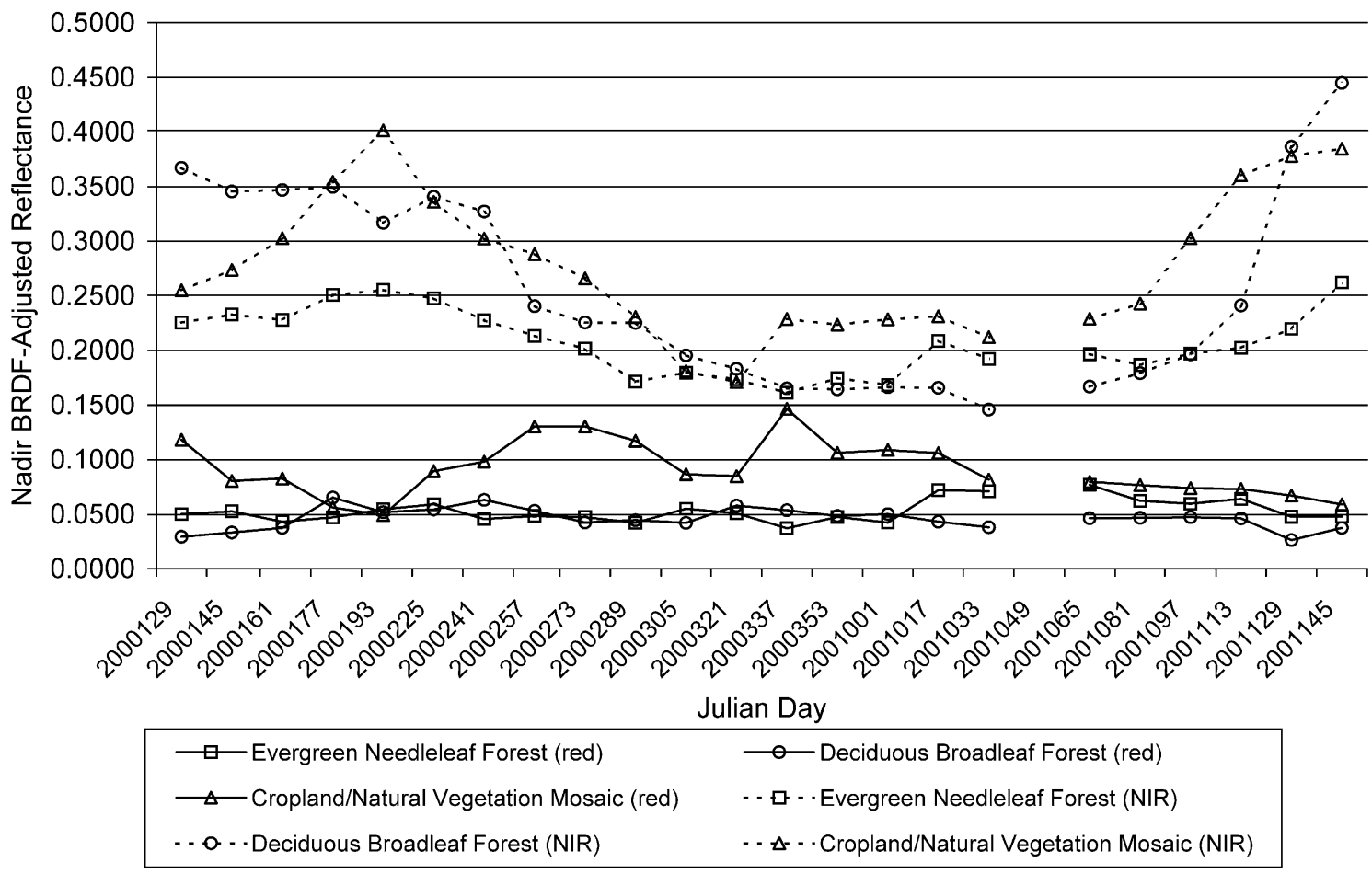

Fig. 4. Temporal trajectories of data from three land cover types in North America, 22 May 2000 to 9 June 2001 (Julian Days 2000129-2001160). 

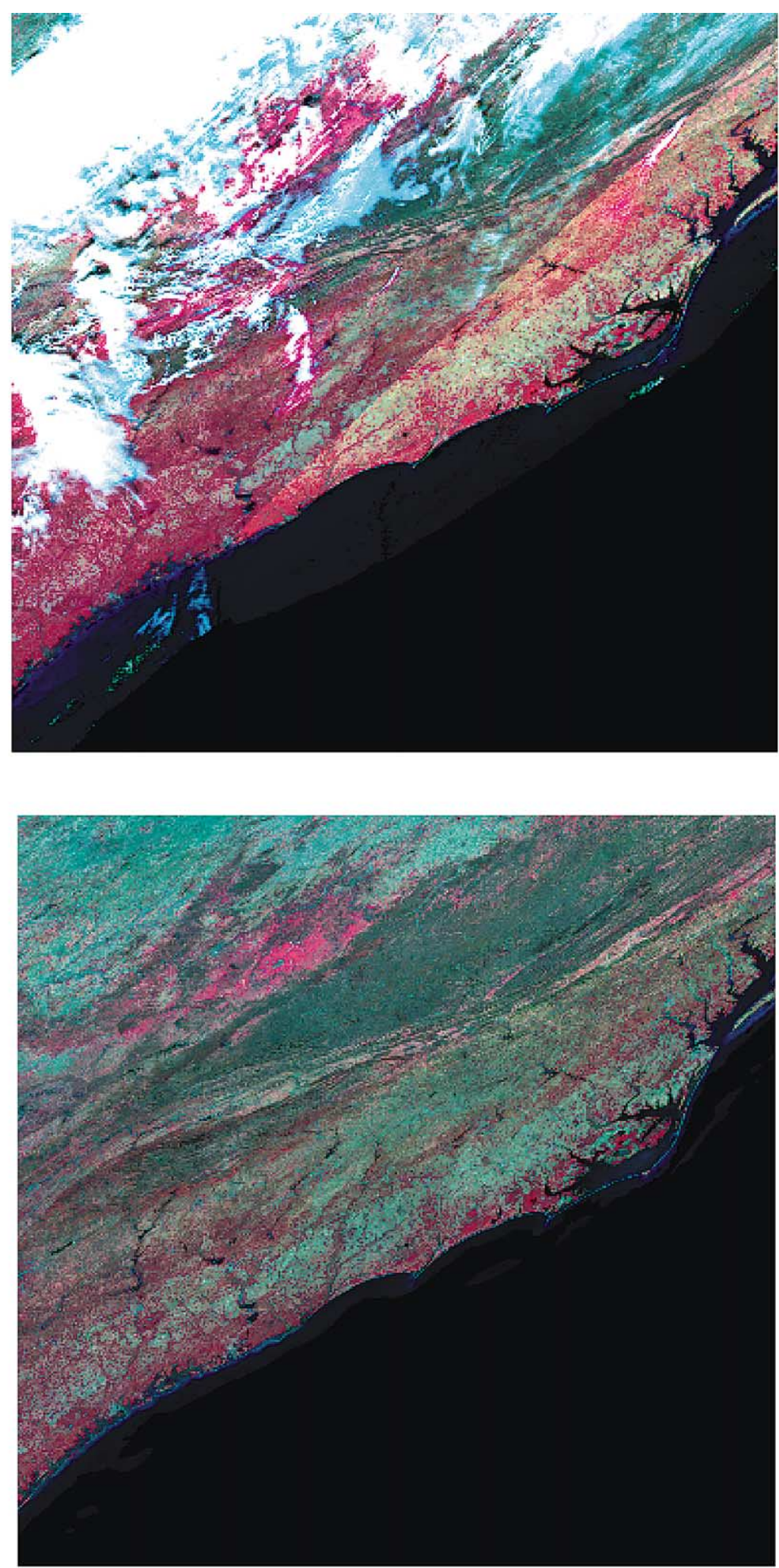

\section{Band 2 -NIR (0.1-0.35) Band 1-Red (0.0-0.12) Band 4-Green (0.0-0.12)}

Fig. 5. Three-channel composite (NIR, Red, Green) of observed surface reflectances of the coast of the Carolina, USA (tile h11v05) for 2 November 2000 (Day 307) (ISG projection; upper image). NBAR for the same tile for the corresponding 16-day period, 31 October to 15 November 2000 (Days 305-320) (lower image). 

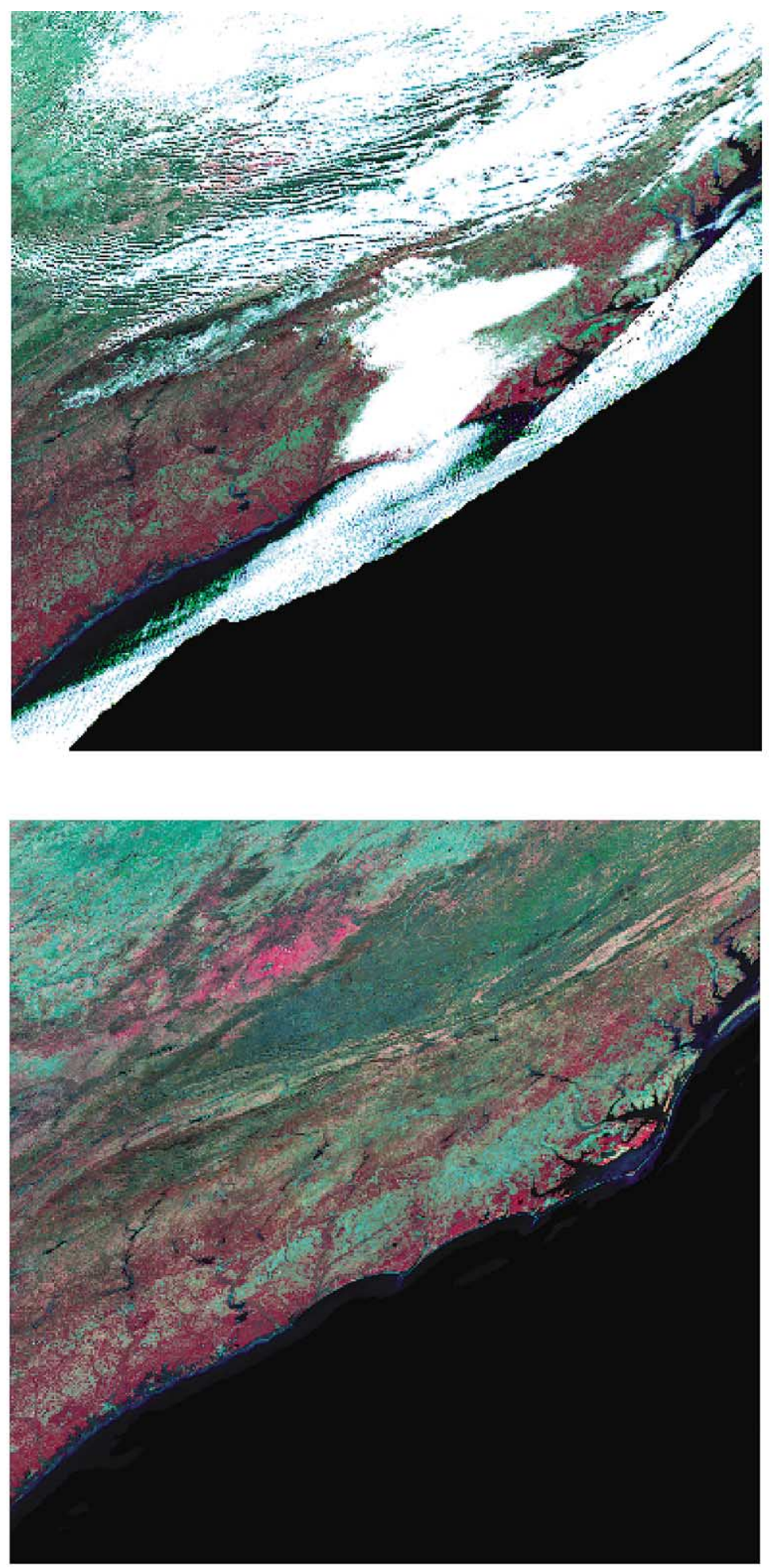

\section{Band 2-NIR (0.1-0.35) Band 1-Red (0.0-0.12) Band 4-Green (0.0-0.12)}

Fig. 6. Three-channel composite of observed surface reflectances from the coast of the Carolinas, USA (tileh11v05) for 20 November 2000 (Day 325 ) (ISG projection; upper image). Predicted reflectances for the viewing and illumination geometries of 20 November, 2000, but derived from the BRDF retrievals of the previous 16-day period, 31 October to 15 November 2000 (Days 305-320) (lower image). 
rection was first introduced at Day 2000273, an instrument improvement was initiated on Day 2000305, and algorithms for the consistent reprocessing were implemented at Day 2001065, is still quite stable and captures the annual vegetation signal of maturity, senescence, dormancy, and growth back to maturity.

The value of using surface reflectances corrected to a nadir viewing geometry is further demonstrated in Fig. 5. A tile of typical daily directional reflectance data (a three channel composite of 2 November 2000) over the coastal Carolinas, USA, is displayed in the upper image (the variations due to cloud and aerosol contamination and the different viewing geometries of adjacent orbits are all clearly visible). This can be compared to the corresponding cloud-free NBAR values with consistent nadir viewing geometries that are shown in the lower image and represent the 16-day period from 31 October to 15 November 2000.

While such qualitative evaluations at global, continental, and biospheric scales are important and demonstrate that the algorithm is performing in a consistent manner, the quality of the BRDF retrievals can be evaluated in a more quantitative fashion by using the BRDF parameters from one 16day period to predict the directional surface reflectances that would be expected during the days of the next period and then comparing these predicted values with the observations actually acquired by the instrument. The upper left image in Fig. 6 displays a spectral composite of directional surface reflectances acquired on 20 November 2000 over the Carolinas. The directional reflectances represent a wide range of viewing zenith and azimuth angles (as shown in the lower left and lower right images in Fig. 7). The directional reflectances are predicted for the 20 November 2000 viewing geometries by using the BRDF model parameters retrieved from the previous period (31 October to 15 November) and these predicted directional surface reflectances are displayed in the lower image of Fig. 6. The quality of this prediction is especially good considering that less than half of the BRDF retrievals were based on full inversions (see the upper left image of Fig. 7). In fact, the cloud-masked portions of the observed image can be
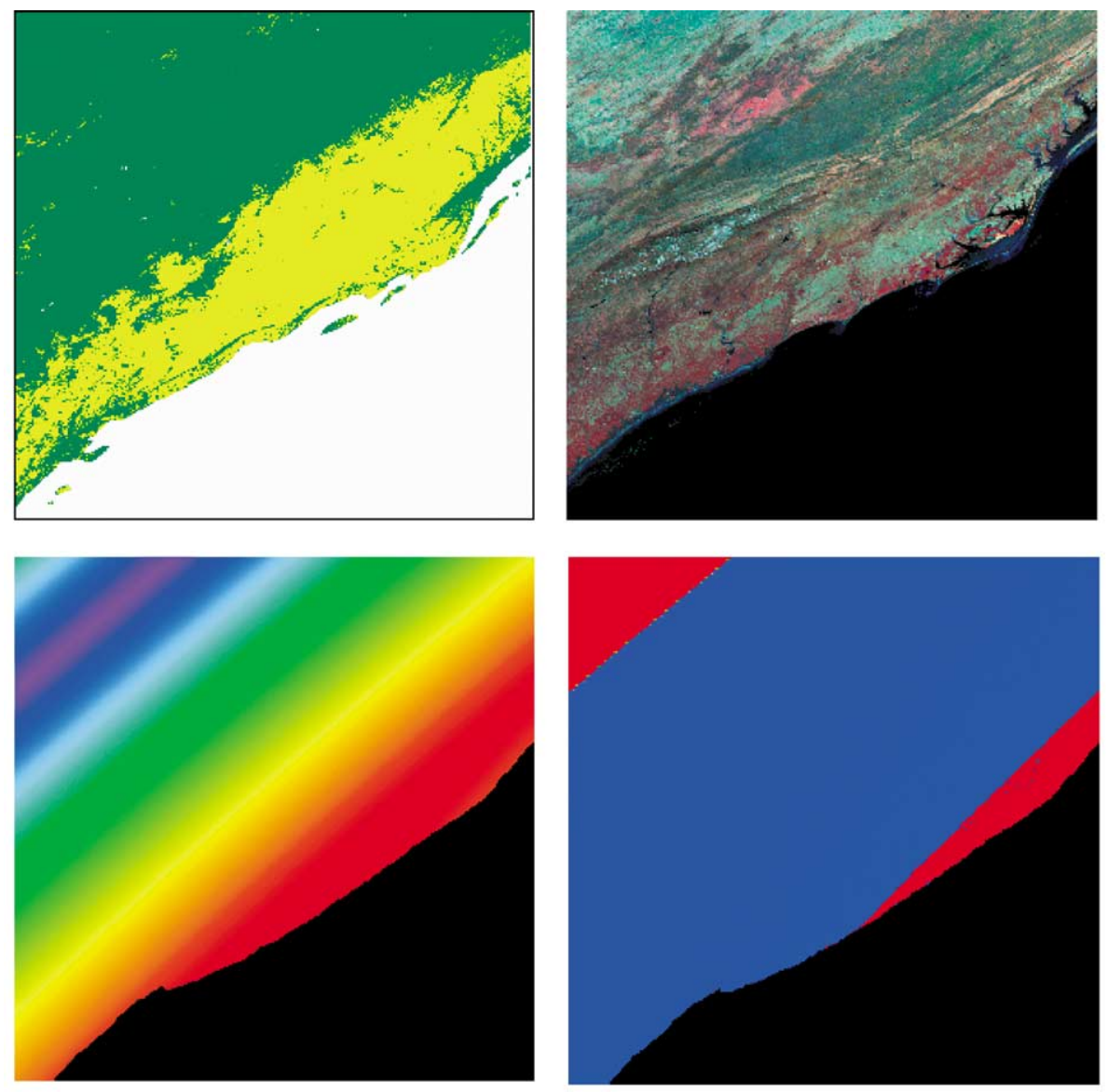

Fig. 7. Proportions of the image in Fig. 6, which were based on full retrievals (yellow) and magnitude retrievals (green) (ISG projection; upper left image). View zenith angles (lower left image) and azimuthal angles (lower right) associated with the 20 November 2000 data. The upper right image uses the observed values for November 20, but replaces the cloudy pixels with the predicted values (thus blending the two images of Fig. 6). 

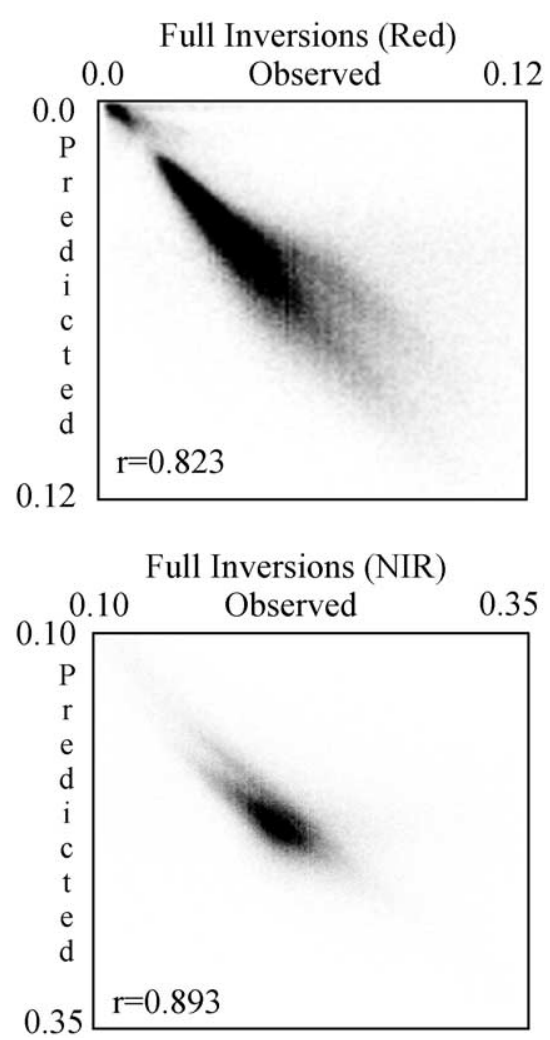
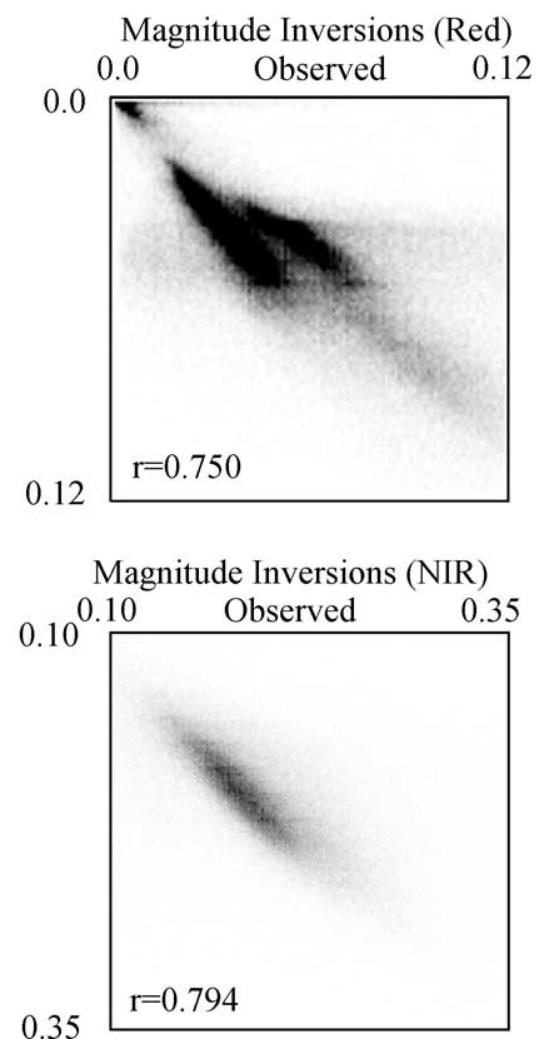

Fig. 8. Scatter plots of the relationship between the red (upper plots) and NIR (lower plots) observed values and the predicted values for the 20 November 2000 data of the Carolinas, USA. Plots for both full inversion values (on the left) and magnitude inversion values (on the right) are given.

replaced with the predicted values and the resulting blended image is quite uniform (as demonstrated in the upper right image of Fig. 7). The correspondence between the full inversion predictions and the actual observations for this 20 November 2000 example are displayed as scatter diagrams for MODIS channels 1 (red) and 2 (NIR) in the left hand charts of Fig. 8. The results for the magnitude inversion predictions are displayed in the right hand charts of Fig. 8. While there is more scatter in the red comparisons than the NIR, the linear relationships are quite good in both cases (correlation coefficient $r$ values of $0.75-0.89$ ).

\section{Summary}

The encouraging results obtained from the first year of operational data have increased overall confidence in the quality of the MODIS BRDF and Albedo Products. The MODIS BRDF/Albedo Product benefits from the availability of seven spectral bands, the on-board calibration of these bands, the extremely accurate geolocation maintained by MODIS, and the coincident characterization of the atmosphere and of clouds (using some of the other 36 channels on board MODIS).

While the ability to obtain sufficient cloud-free surface reflectances presents a challenge during certain seasons and over certain regions, the MODIS BRDF/Albedo algorithm's use of magnitude inversions which utilize a priori knowledge of the likely anisotropy of the surface reflectance, supplements the full inversion results and guarantees reliable and temporally consistent global products. As we move into the Terra post-launch era, the addition of both MISR data from Terra and additional MODIS data from Aqua will further enhance the quality and stability of the operational BRDF and albedo products. With completion of the field exercises currently underway, fully validated MODIS BRDF/Albedo Products will be made available to the general public.

\section{Acknowledgements}

This work was supported by NASA under NAS5-31369 as part of the EOS-MODIS project. Funding in the UK was partially provided by NERC. Thanks are due to all of the members of the MODIS Science Team and especially the MODLAND group. We are dependent on the fine work of Steve Ackerman (MODIS Cloud Mask), Eric Vermote (MODIS surface reflectance) and Kamel Didan (MODIS surface reflectance aggregation) in supplying us with high quality input data. Robert Wolfe, Nazmi El Saleous, Sadashiva Devadiga, Jordan Borak, Jacques Decloitres, and Jeff Morisette deserve special recognition for their efforts to ensure the quality of the MODIS BRDF/Albedo 
Product. We also appreciate the many discussions we've had with Dave Diner, Carol Bruegge, John Martonchik and our colleagues on the MISR Team, Mark Chopping, Anne Nolin, Ranga Myneni, Yuri Knyazikhin, Curtis Woodcock, Gerhard Meister, Wenge Ni, David Meyer, John Miller, Jean-Louis Roujean, Marc Leroy and our colleagues on the POLDER team.

\section{References}

Barnsley, M. J., Hobson, P. D., Hyman, A. H., Lucht, W., Muller, J.-P., \& Strahler, A. H. (2000). Characterizing the spatial variability of broadband albedo in a semi-desert environment for MODIS validation. Remote Sens. Environ., 74, 58-68.

Chopping, M. J. (1999). Large-scale BRDF retrieval over New Mexico with a multiangular NOAA AVHRR dataset. Remote Sens. Environ., 74, $164-192$.

Deering, D. W., \& Leone, P. (1986). A sphere-scanning radiometer for rapid directional measurements of sky and ground reflectance. Remote Sens. Environ., 19, 1-24.

d'Entremont, R. E., Barker Schaaf, C. L., Lucht, W., \& Strahler, A. H. (1999). Retrieval of red spectral albedo and bi-directional reflectance using AVHRR HRPT and GOES satellite observations of the New England region. J. Geophys. Res., D-104, 6229-6239.

Diner, D. J., Asner, G. P., Davies, R., Knyazikhin, Y., Muller, J.-P., Nolin, A., Pinty, B., Schaaf, C. B., \& Stroeve, J. (1999). New directions in Earth observing: scientific applications of multi-angle remote sensing. Bull. Am. Meteorol. Soc., 80, 2209-2228.

Diner, D. J., Beckert, J. C., Reilly, T. H., Bruegge, C. J., Conel, J. E., Kahn, R. A., Martonchik, J. V., Ackerman, T. P., Davies, R., Gerstl, S. A. W., Gordon, H. R., Muller, J.-P., Myneni, R. B., Sellers, P. J., Pinty, B., \& Verstraete, M. M. (1998). Multi-angle imaging spectroradiometer (MISR) instrument description and experiment overview. IEEE Trans. Geosci. Remote Sens., 36, 1072-1087.

Friedl, M. A., Muchoney, D., McIver, D., Gao, F., Hodges, J. F. C., \& Strahler, A. H. (2000). Characterization of North American land cover from NOAA-AVHRR data using the EOS MODIS land cover classification algorithm. Geophys. Res. Lett., 27, 977-980.

Hautecoeur, O., \& Leroy, M. M. (1998). Surface bi-directional reflectance distribution function observed at global scale by POLDER/ADEOS. Geophys. Res. Lett., 22, 4197-4200.

Hu, B., Lucht, W., Strahler, A., Schaaf, C., \& Smith, M. (2000). Surface albedos and angle-corrected NDVI from AVHRR observations of South America. Remote Sens. Environ., 71, 119-132.

Justice, C. O., Vermote, E., Townshend, J. R. G., DeFries, R., Roy, D. P., Hall, D. K., Salomonson, V. V., Privette, J. L., Riggs, G., Strahler, A., Lucht, W., Myneni, R. B., Knjazikhin, Y., Running, S. W., Nemani, R. R., Wan, Z., Huete, A. R., van Leeuwen, W., Wolfe, R. E., Giglio, L., Muller, J.-P., Lewis, P., \& Barnsley, M. J. (1998). The Moderate Resolution Imaging Spectroradiometer (MODIS): land remote sensing for global change research. IEEE Trans. Geosci. Remote Sens., 36, $1228-1249$

Leroy, M., Deuze, J. L., Breon, F. M., Hautecoeur, O., Herman, M., Buriez, J. C., Tanre, D., Bouffies, S., Chazette, P., \& Roujean, J.-L. (1997). Retrieval of atmospheric properties and surface bidirectional reflectances over land from POLDER/ADEOS. J. Geophys. Res., 102, $17023-17037$.

Lewis, P., \& Barnsley, M. J. (1994). Influence of the sky radiance distribution on various formulations of the earth surface albedo. Proc. Conf. Phys. Meas. Sign. Remote Sen. Val d'Isere, France. (pp. 707-715).

Lewis, P., Disney, M. I., Barnsley, M. J., \& Muller, J.-P. (1999). Deriving albedo maps for HAPEX-Sahel from ASAS data using kernel-driven BRDF models. Hydrol. Earth Syst. Sci., 3, 1-13.
Li, X., \& Strahler, A. H. (1992). Geometric-optical bidirectional reflectance modeling of the discrete crown vegetation canopy: effect of crown shape and mutual shadowing. IEEE Trans. Geosci. Remote Sens., 30, $276-292$

Liang, S., Strahler, A. H., \& Walthall, C. W. (1999). Retrieval of land surface albedo from satellite observations: a simulation study. J. Appl. Meteorol., 38, 712-725.

Loveland, T. R., Reed, B. C., Brown, J. F., Ohlen, D. O., Zhu, J., Yang, L., \& Merchant, J. W. (1999). An analysis of the IGBP global land-cover characterization process. Photogramm. Eng. Remote Sensing, 65, $1021-1032$.

Lucht, W. (1998). Expected retrieval accuracies of bi-directional reflectance and albedo from EOS-MODIS and MISR angular sampling. J. Geophys. Res., 103, 8763-8778.

Lucht, W., Hyman, A. H., Strahler, A. H., Barnsley, M. J., Hobson, P., \& Muller, J.-P. (2000). A comparison of satellite-derived spectral albedos to ground-based broadband albedo measurements modelled to satellite spatial scale for a semi-desert landscape. Remote Sens. Environ., 74, $85-98$.

Lucht, W., \& Lewis, P. (2000). Theoretical noise sensitivity of BRDF and albedo retrieval from the EOS-MODIS and MISR sensors with respect to angular sampling. Int. J. Remote Sensing, 21, 81-98

Lucht, W., \& Roujean, J.-L. (2000). Considerations in the parametric modeling of BRDF and Albedo from multiangular satellite sensor observations. Remote Sens. Rev., 18, 343-379.

Lucht, W., Schaaf, C. B., \& Strahler, A. H. (2000). An Algorithm for the retrieval of albedo from space using semiempirical BRDF models. IEEE Trans. Geosci., Remote Sens., 38, 977-998.

Martonchik, J. V., Diner, D. J., Pinty, B., Verstraete, M. M., Myneni, R. B., Knjazikhin, Y., \& Gordon, H. R. (1998). Determination of land and ocean reflective, radiative, and biophysical properties using multiangle imaging. IEEE Trans. Geosci. Remote Sens., 36, 1266-1281.

Muchoney, D., Strahler, A. H., Hodges, J. C. F., \& LoCastro, J. (1999). The IGBP DISCover confidence sites and the system for terrestrial ecosystem parameterization: tools for validating global land-cover data. Photogramm. Eng. Remote Sensing, 65, 1061-1067.

Nilson, T., \& Kuusk, A. (1989). A reflectance model for the homogenous plant canopy and its inversion. Remote Sens. Environ., 27, 157-167.

Olson, J. S. (1994). Global ecosystem framework: definitions. Internal report, USGS EROS Data Center, Sioux Falls, SD, 37 pp.

Pinty, B., Roveda, F., Verstraete, M. M., Gobron, N., Govaerts, Y., Martonchik, J. V., Diner, D. J., \& Kahn, R. A. (2000a). Surface albedo retrieval from METEOSAT: Part 1. Theory. J. Geophys. Res., D-105, $18099-18112$.

Pinty, B., Roveda, F., Verstraete, M. M., Gobron, N., Govaerts, Y., Martonchik, J. V., Diner, D. J., \& Kahn, R. A. (2000b). Surface Albedo Retrieval from METEOSAT: Part 2. Applications. J. Geophys. Res., D$105,18113-18134$.

Privette, J. L., Eck, T. F., \& Deering, D. W. (1997). Estimating spectral albedo and nadir reflectance through inversion of simple BRDF models with AVHRR/MODIS-like data. J. Geophys. Res., D-102, 29529-29542.

Privette, J. L., Morrisette, J. T., Justice, C., \& Starr, D. (1999). EOS Global Land Validation Network. Proc. Int. Geosci. Remote Sens., Symp. (IGARSS '99), Hamburg, Germany, 28 June-2 July.

Rahman, H., Pinty, B., \& Verstraete, M. M. (1993). Coupled surfaceatmosphere reflectance (CSAR) model, 2, Semiempirical surface model usable with NOAA advanced very high resolution radiometer data. $J$. Geophys. Res., D-98, 20791-20801.

Ross, J. K. (1981). The radiation regime and architecture of plant stands. Norwell, MA: Dr. W. Junk (392 pp.).

Roujean, J.-L., Leroy, M., \& Deschamps, P. Y. (1992). A bi-directional reflectance model of the Earth's surface for the correction of remote sensing data. J. Geophys. Res., D-97, 20455-20468.

Strugnell, N., \& Lucht, W. (2001). Continental-scale albedo inferred from AVHRR data, land cover class and field observations of typical BRDFs. J. Clim., 14, 1360-1376 
Strugnell, N., Lucht, W., \& Schaaf, C. (2001). A global albedo data set derived from AVHRR data for use in climate simulations. Geophys. Res. Lett., 28, 191-194.

Vermote, E. F., El Saleous, N., Justice, C. O., Kaufman, Y. F., Privette, J. L., Remer, L., Roger, J. C., \& Tanre, D. (1997). Atmospheric correction of visible to middle infrared EOS-MODIS data over land surfaces: background, operational algorithm, and validation. J. Geophys. Res., D-102, $17131-17141$.

Wanner, W., Li, X., \& Strahler, A. H. (1995). On the derivation of kernels for kernel-driven models of bi-directional reflectance. J. Geophys. Res., D-100, 21077-21090.

Wanner, W., Strahler, A. H., Hu, B., Lewis, P., Muller, J.-P., Li, X., Barker Schaaf, C. L., \& Barnsley, M. J. (1997). Global retrieval of bidirectional reflectance and albedo over land from EOS MODIS and MISR data: theory and algorithm. J. Geophys. Res., D-102, 17143-17162.

Wolfe, R. E., Roy, D. P., \& Vermote, E. (1998). MODIS land data storage, gridding, and compositing methodology: level 2 grid. IEEE Trans. Geosci. Remote Sens., 36, 1324-1338. 